the auspices of the Native Affairs Department, and pointing to the problems which arise from the development side by side of the white and black populations, it seems that he advocates the formation of a dominion in which the interests of the black population would be paramount. Such a dominion, which would permit of the civil and political development to the full of the black population, might, it is suggested, comprise the present territories of Uganda, Tanganyika, Nyasaland and Northern Rhodesia, where white settlement and development have not reached a stage, such as that, for example, in Kenya and Southern Rhodesia, which would prove an insuperable obstacle to this policy. Inevitably, some sacrifice would be involved, but in other areas, in compensation, the interests of the white population would be recognised as paramount. Col. Carbutt stresses the argument, of which indeed the force must be patent to everyone, that a solution of the native problem is vital for the future of the commonwealth of British peoples, and at the same time maintains that such a solution as he suggests would be acceptable to, and indeed welcomed by, the natives themselves. It would appear already to have been received with some measure of approval in Africa, if mainly as representing an advance toward the idea of a federation of the two Rhodesias and Nyasaland, or even of a united East and South Africa.

THE proposal that a dominion should be formed north of the Zambezi constituting what would be, virtually, a vast self-governing reserve for native tribes is an adaptation to conditions in East and South Africa of a proposal put forward some years ago by the late Prof. J. W. Gregory. Prof. Gregory, who was convinced that, on the whole, intimate contact between white and coloured races was harmful to both, thought that the solution of the world's racial problem lay in some such territorial segregation of the white and the coloured races according to their respective adaptation to climatic and other conditions. The black races were to be confined mainly to the tropical belt. The proposal now put forward by Col. Carbutt has the merit that while it might follow as a logical development of the policies of segregation and 'indirect rule', it would afford opportunities for cultural, political and economic development of the native along the lines of his own institutions and without too abrupt a break with tradition, such as will be, it is becoming increasingly obvious, if not impossible, at any rate extremely difficult to secure in present conditions. Clearly the political status of such a dominion would have to be such as to entail a lengthy period of tutelage, pending the attainment by the native of an adequate measure of competence in the conduct of affairs, and to ensure avoidance of difficulties such as have arisen in Liberia.

\section{Science and Armaments}

IN an address before the Bristol Section of the Institute of Chemistry on December 10, Dr. Herbert Levinstein asserted that the destructive power of science in war is absurdly overrated, and that the application of chemical science to war has not made war more dangerous either to soldiers or to civilians. $\mathrm{He}$ argued further that scientific warfare is more humane and, because its continual inventiveness introduces an element of surprise, is more likely to bring a war to an early conclusion. The great wastage of life in the War of 1914-18 was due to lack of invention, to reliance on mere numbers of men or projectiles and on obsolete tactics. Dr. Levinstein stressed further the close connexion between chemical industry and chemical warfare, asserting that the prohibition of chemical warfare in the Treaty of Versailles was not due to the horrors of such warfare but to disparity in strength between German chemical industry and that of other countries. He regards as unworkable the suggestion that chemists should agree not to produce any substance used for warlike purposes, because differences between warlike and nonwarlike substances are too subtle to be effective.

Dr. Levinstern's address was doubtless provocative by design but to what purpose is obscure. A discussion on the relative humanity of various methods of warfare is as futile and beside the mark as it is unscientific. Moreover, chemical industry at the present time is scarcely so undeveloped in Great Britain as to merit the rather dubious support which its relation to chemical warfare may lend it. A satisfactory and scientific approach to armament, as to disarmament, is that indicated by Major Lefebure in his book "Scientific Disarmament". The piecemeal discussion of this difficult question is always dangerous and Dr. Levinstein's treatment goes far to nullify the value of his warning that the possibility of chemical warfare cannot be excluded merely by treaty provisions. The moral aspects of the participation of the scientific worker in preparation for warfare were rather too lightly dismissed by Dr. Levinstein, whose remarks here were all the more disappointing because of the need for clear thinking and close discussion by scientific men of this important matter. The creation of a definite professional opinion and code may be a slow process, but it should not be dismissed as impossible. On the other hand, there are definite spheres in which the chemist and other scientific workers can render important services in national defence to which no suggestion of extending the area of conflict can be attached. One such proposal is contained in a long article in the Retail Chemist for December in which an organisation of all the chemists of the country to deal with the effects of poison gas attack on the civilian population is advocated. The First Aid posts for gas casualties suggested by Major-Gen. P. S. Wilkinson, of the Order of St. John of Jerusalem, is another such practical proposal in which the knowledge and experience of the chemist might be of direct service to the community.

\section{Artificial Nuclear Transmutations}

LORD RUtherford, in his Ludwig Mond lecture at the University of Manchester on December 10 , described how recent work in the study of artificial nuclear transmutations is giving rise to a new 